\title{
Ultra-fast firing: effect of heating rate on sintering of 3YSZ, with and without an electric field
}

\author{
W. Ji ${ }^{1,3}$, B. Parker ${ }^{1}$, S. Falco ${ }^{2}$, J.Y. Zhang ${ }^{3}$, Z.Y. Fu ${ }^{3}$ and R.I. Todd ${ }^{1 *}$
}

${ }^{1}$ University of Oxford, Department of Materials, Parks Road, Oxford OX1 3PH, UK.

${ }^{2}$ University of Oxford, Department of Engineering Science, Oxford OX1 3PJ, UK.

${ }^{3}$ State Key Laboratory of Advanced Technology for Materials Synthesis and Processing, Wuhan University of Technology, Wuhan 430070, China.

*Corresponding author: richard.todd@materials.ox.ac.uk

Keywords: flash sintering; fast firing; ysz; FAST; Joule heating

\begin{abstract}
It has recently been reported that ceramics can be sintered in a few seconds with the aid of an electric field ("flash sintering"). This investigation tests the possibility that the accelerated sintering is a consequence of the rapid heating rate involved rather than a direct effect of the electric field on mass transport. The sintering of 3 YSZ powder compacts at a temperature of $\sim 1300{ }^{\circ} \mathrm{C}$ was compared (i) in flash sintering, (ii) with rapid heating rates produced without the application of an electric field, and (iii) with conventional heating rates. The results show that rapid heating can accelerate sintering by over 2 orders of magnitude compared with heating to the same temperature at conventional rates, even without the application of an electric field. It is concluded that the rapid densification in flash sintering of 3 YSZ is at least partly a consequence of the rapid heating involved. Possible explanations are discussed.
\end{abstract}

\section{Introduction}

The sintering of ceramics, in which a compact of inorganic particles is transformed to a dense, bulk artefact by the application of heat, is one of the oldest human technologies, having been practised for at least 28000 years [1]. For most of this long history, the duration of the firing process has been many hours or even several days. In contrast, it has recently been reported that ceramics can be sintered in 
just a few seconds by the application of an electric field to a pre-heated powder compact [2]. Its originators have termed this "flash sintering".

There is general agreement that densification in flash sintering coincides with the sudden passage of an electric current through the specimen in response to the applied field, leading to rapid resistive (Joule) heating. There is also a growing consensus that this electrical response originates in classical thermal runaway as the resistivity progressively reduces in response to the heating, so leading to increased " $V$ 2/R" power dissipation and consequently to higher heating rate [3-7].

The reason for the high rate of densification itself is less clear. Most suggestions have proposed that it is related in some way to the electricity involved, e.g. through local Joule heating at grain boundaries $[2,8]$ or the nucleation of charged defects under the action of the field [9]. It has been known for over 50 years, however, that in "fast firing", rapid heating rates to high temperatures in the absence of electric fields can also lead to enhanced sintering compared with the results of the slow heating rates used conventionally [10-14]. Since unusually rapid heating is also a prominent characteristic of flash sintering, it is conceivable that it is this, rather than the presence of an electric field, which is responsible for the rapid densification observed.

The simple aim of the research described here was to investigate this possibility by comparing the sintering obtained in flash sintering with that obtained using similar, rapid heating schedules but in which the heating was produced by methods which did not subject the specimens to electric fields. Results using conventional, slow heating are also reported for comparison. Slip cast green bodies of the same powder were used in all cases and the maximum temperature was also as nearly as possible the same in all cases $\left(\sim 1300^{\circ} \mathrm{C}\right)$ so that the only differences in the temperature profiles were in the heating 
and cooling rates. The ceramic chosen for the investigation was 3 mol\% yttria-stabilised zirconia (3YSZ) because this was used in the first report of flash sintering [2] and is the most studied composition.

\section{Experimental}

Materials.

All the experiments in this work used a commercial 3YSZ powder (TZ-3Y-E, Tosoh, Japan) as the starting material. The particle size of the powder is $60 \mathrm{~nm}$ and the density of ceramics sintered from the powder under optimal conditions is $6.05 \mathrm{~g} / \mathrm{cm}^{3}$, as reported by the supplier.

The specimens for flash sintering (FS) were bars made by slip casting of slurries consisting of 55 wt. \% 3YSZ powder and 1 wt. \% Dispex A40 dispersant in distilled water. An ultrasonic probe was used to break up any agglomerates before casting the slurry into plastic moulds on a porous gypsum base. Metallic pins of $1 \mathrm{~mm}$ in diameter were set in the specimen separated by a distance of $\sim 20 \mathrm{~mm}$ and removed before the samples were completely dried to leave holes for electrical connections and mechanical support (Fig. 1). Two platinum wires were set at points between the holes for "4-point" recording of the electric field in the central part of the specimen, eliminating the effect of contact resistance at the outer connections. The specimen thickness was $\sim 2 \mathrm{~mm}$. Final drying was in an oven at $80^{\circ} \mathrm{C}$. The resulting green bodies were approximately $55 \%$ dense.

The specimens for all the other sintering methods (self-propagating high-temperature synthesis (SHS), furnace insertion $(\mathrm{FI})$ and conventional furnace heating $(\mathrm{CH})$ ) were smaller pieces of identical green samples with dimensions of only a few $\mathrm{mm}$ in order to allow external heating to permeate the sample as quickly as possible and so that thermal shock and the inhibition of sintering by differential densification [15] could be avoided. 
The specimens for flash sintering were additionally pre-fired for $1 \mathrm{~h}$ at $750{ }^{\circ} \mathrm{C}$ to give them enough strength to be handled. Stripes of platinum paste were then painted around the specimen intersecting the holes as shown in Fig. 1 to provide electrodes. The interior walls of the holes were also coated with paste.

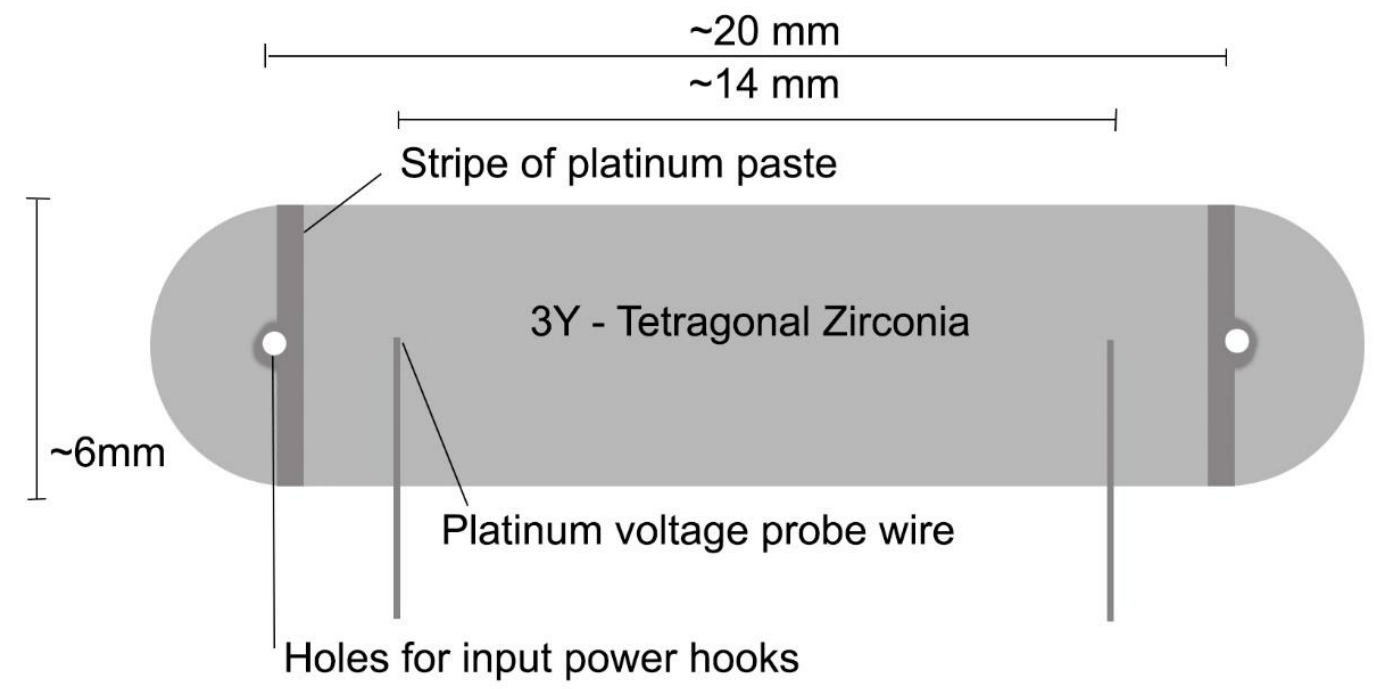

Figure 1. Geometry of flash sintering specimens.

Sintering.

FS: Experiments in which electric fields were applied to ceramic specimens through a closed electrical circuit were carried out in a modified box furnace [3]. A commercial DC power source (360 V, 15 A, 1500 W, Elektro-Automatik, Viersen, Germany) was used and the data were logged using a NI USB 6008 data logger in conjunction with Labview software. The specimens were suspended from two platinum wires hung over an alumina frame and inserted into the holes near the specimen ends with some platinum paste to ensure electrical connection. The furnace was heated at a rate of $7.5^{\circ} \mathrm{C} / \mathrm{min}$ to $600{ }^{\circ} \mathrm{C}$ and then at $5{ }^{\circ} \mathrm{C} / \mathrm{min}$ to the hold temperature of $950{ }^{\circ} \mathrm{C}$, as measured by the furnace thermocouple. The actual furnace temperature at the specimen position was found to be $925^{\circ} \mathrm{C}$. When the furnace had reached 
this temperature, an initial electric field of $150 \mathrm{~V} / \mathrm{cm}$ was applied in all the flash sintering runs. The power supply was programmed to apply a constant voltage but was switched automatically to current control when a current of $0.5 \mathrm{~A}$ was reached. The current was switched off $0 \mathrm{~s}, 10 \mathrm{~s}$ or $30 \mathrm{~s}$ after the switch to current control.

Specimen temperatures during the FS experiments were estimated using a non-equilibrium development of the black body radiation model of Raj [16] as follows. Assuming that radiative heat loss dominates, the temperature increase of the section of the specimen between the voltage probe wires with surface area $A$ in time increment $\delta t$ is:

$$
\frac{\mathrm{d} T_{s}}{\mathrm{~d} t}=\frac{V I-A \sigma \varepsilon\left(T_{s}^{4}-T_{f}^{4}\right)}{m c_{p}}
$$

so that:

$T_{s}=T_{f}+\int_{0}^{t} \frac{V I-A \sigma \varepsilon\left(T_{s}^{4}-T_{f}^{4}\right)}{m c_{p}} \mathrm{~d} t$

where $V$ is voltage between the probe wires, $I$ is current, $\sigma$ is Stefan's constant, $\varepsilon$ is the emissivity, taken as 0.9 in this work, $T_{s}$ and $T_{f}$ are the temperatures of the specimen and furnace the respectively, $m$ is the mass and $c_{p}=600 \mathrm{~J} \mathrm{~kg}^{-1} \mathrm{~K}^{-1}[17]$ is the heat capacity of 3YSZ.

The electrical power $W$ was sampled 200 times per second and equation (2) was solved numerically for $T_{s}$ as a function of $t$ from the start of electrical heating $\left(T_{s}=T_{f}\right)$ using the experimental values of electrical power against time, updating $T_{s}$ after each time increment. At steady state, eq. (1) $=0$ and the specimen temperature is the same as that estimated by Raj [16]. The method is complicated by the change in $A$ resulting from sintering shrinkage. In the present work, only the peak value of $T_{s}$ in the central part of the specimen between the voltage probe wires and the steady state value are quoted. The peak value 
was reached soon after the switch to constant current and was estimated using the green body specimen dimensions, ignoring the small amount of sintering at this stage. The steady state estimate used the sintered dimensions.

SHS: In this work, the exothermic SHS reaction between $\mathrm{Ni}$ and $\mathrm{Al}$ powders was used as the thermal source to heat the 3YSZ compacts. The SHS reactants consisted of $\mathrm{Ni}(74 \mu \mathrm{m}, 99.8 \%)$ and $\mathrm{Al}(29 \mu \mathrm{m}$, 98.7\%) powders in a molar ratio of 1:1, with 25 mol. \% inert diluent (TiC, $2 \mu \mathrm{m}, 99.5 \%$ ) added to adjust the temperature profile at the specimen to a peak temperature of around $1300^{\circ} \mathrm{C}$. The $3 Y S Z$ compact to be sintered was wrapped in a thin layer of graphite foil to prevent contamination and packed within the SHS reactants. The reactants were ignited by an energised tungsten filament far from the specimen, causing a combustion wave to pass through the reactants around the compact, resulting in rapid heating. The temperature was monitored by a C type thermocouple adjacent to the specimen. Only two SHS results are shown in the present work because it is difficult to adjust the dwell time significantly without changing the maximum temperature but several similar tests showed the results to be reproducible.

FI and $\mathrm{CH}$ : The $\mathrm{FI}$ and $\mathrm{CH}$ experiments were carried out in a tube furnace in air with a steady state temperature of $1315^{\circ} \mathrm{C}$ (measured using an independent thermocouple at the specimen position). To obtain the highest heating rates possible in the $\mathrm{Fl}$ experiments, the samples were attached to a thermocouple which was used to insert them rapidly to the same location in the ready-heated furnace as was used for the $\mathrm{CH}$ specimens as well as to monitor the specimen temperature. After sintering for various times ( $30 \mathrm{~s}, 1 \mathrm{~min}, 2 \mathrm{~min}, 3 \mathrm{~min}$ and $5 \mathrm{~min}$ after insertion), the samples were withdrawn quickly from the furnace and cooled in air. 
For $\mathrm{CH}$, the specimens were heated from room temperature to the dwell temperature of $1315{ }^{\circ} \mathrm{C}$ and back again with a heating/cooling rate of $5{ }^{\circ} \mathrm{C} / \mathrm{min}$. The dwell times of the two $\mathrm{CH}$ specimens reported here were $3 \mathrm{~min}$ and 1 hour.

Sintered densities were measured by the Archimedes method.

Table 1. Comparison of heating schedules for the different heating methods. *SHS specimens had no steady state. ${ }^{* *}$ The "Os" FS specimen only reached an estimated maximum temperature of $1276{ }^{\circ} \mathrm{C}$.

\begin{tabular}{|l|l|l|l|}
\hline heating method & $\begin{array}{l}\text { maximum } \\
\text { temperature }\end{array}$ & $\begin{array}{l}\text { steady state } \\
\text { temperature }\end{array}$ & $\begin{array}{l}\text { nominal heating rate } \\
950-1250^{\circ} \mathrm{C}\end{array}$ \\
\hline SHS (1) & ${ }^{\circ} \mathrm{C}$ & ${ }^{\circ} \mathrm{C}$ & ${ }^{\circ} \mathrm{C} / \mathrm{s}$ \\
\hline SHS (2) & 1301 & $\mathrm{n} / \mathrm{a}^{*}$ & 339 \\
\hline flash sintering (FS) & 1287 & $\mathrm{n} / \mathrm{a}^{*}$ & 125 \\
\hline furnace insertion (FI) & $1347^{* *}$ & 1280 & 94 \\
\hline conventional heating (CH) & 1315 & 1315 & 50 \\
\hline
\end{tabular}




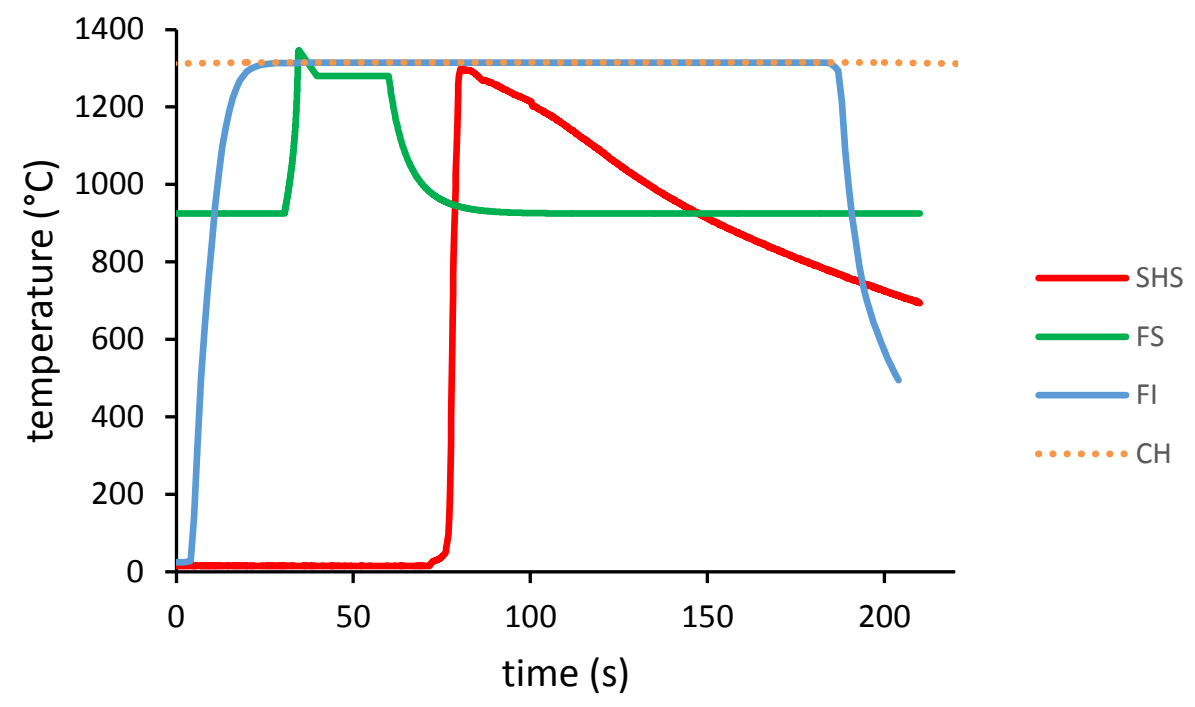

Figure 2 (Colour online). Typical temperature-time profiles for the different heating methods. The results shown are: SHS (1), FS with 30 s under current control, FI with 3 minute insertion, CH with 3 minute dwell (between 20 and 200 s on the plot). Start times are offset for clarity.

\section{Results}

Heating rates. Table 1 shows the measured temperatures and heating rates obtained using the different heating methods and Figure 2 compares the corresponding temperature-time profiles.

The SHS specimens showed a maximum in the temperature as the combustion wave passed by, followed by rapid cooling. For the SHS(1) specimen, for example, the cooling time was $5 \mathrm{~s}$ from the maximum of $1301{ }^{\circ} \mathrm{C}$ to $1275^{\circ} \mathrm{C}$, and was $21 \mathrm{~s}$ from $1301{ }^{\circ} \mathrm{C}$ to $1200^{\circ} \mathrm{C}$.

The estimated temperatures for the flash sintered specimens showed a maximum before the steady state "Region III" period at constant current. This is thought to be because sintering reduces the resistance and therefore the "I $\mathrm{R}^{2}$ " Joule heating decreases during the constant current phase. 
The non-conventional heating rates exceeded the conventional heating rate by between 2 and 4 orders of magnitude. After $\mathrm{CH}$, the order of increasing heating rate was $\mathrm{FI}$ then FS followed by SHS. In practice, the internal heating of the SHS specimens must have been slower than is suggested by the values from the external thermocouple in Table 1 owing to the limitations of heat transfer through the barrier layer and into the specimen interior. A similar approach to that of eqs. (1) and (2) but with $\mathrm{VI}=0$ suggests that $100^{\circ} \mathrm{C} / \mathrm{s}$ is a more realistic value for the SHS(1) specimen, i.e. similar to the FS specimen.

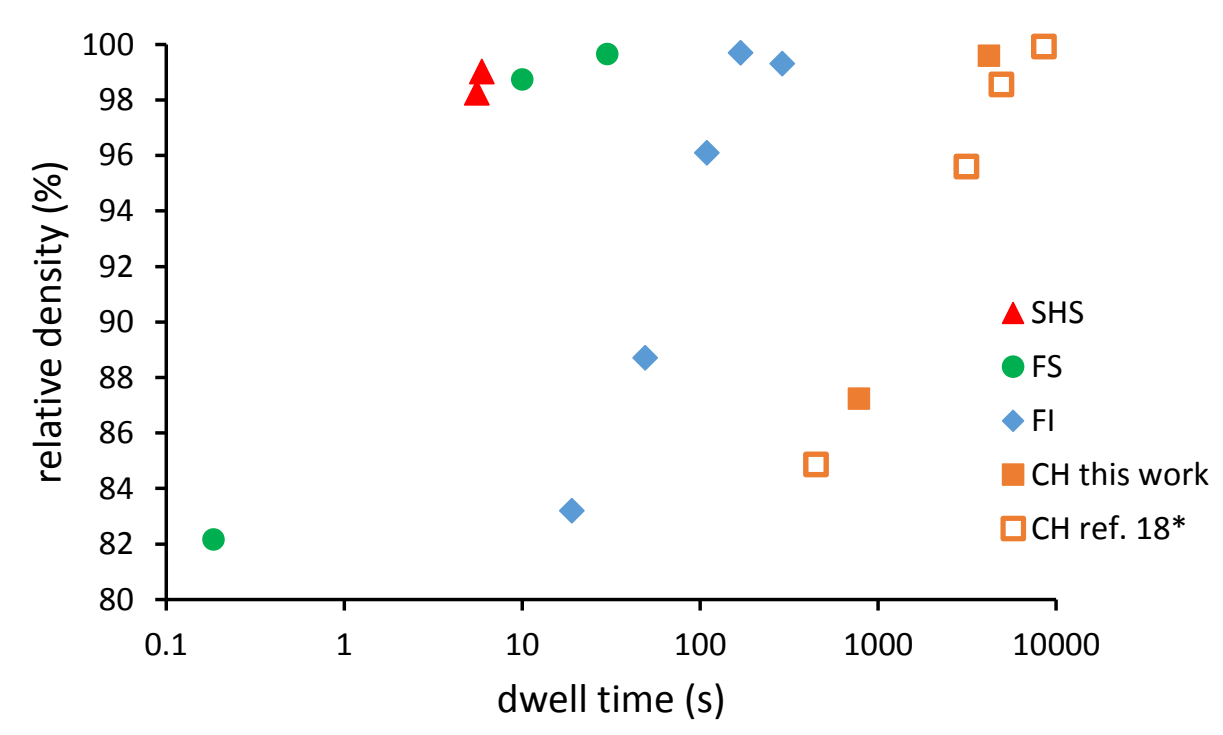

Figure 3. Relative density against time with temperature $T \geq 1275^{\circ} \mathrm{C}$ for specimens heated to a temperature of $\sim 1300^{\circ} \mathrm{C}$ using methods with different heating rates. ( ${ }^{*}$ The " $\mathrm{CH}$ ref. [18]" data points are for a temperature of $1300{ }^{\circ} \mathrm{C}$ from Fig. 5 of reference [18] and have been adjusted to be consistent with the value of theoretical density assumed here).

Sintering results. Figure 3 shows a semi-logarithmic plot of the relative density as a function of nominal dwell time at $\sim 1300{ }^{\circ} \mathrm{C}$ for specimens with different heating rates. Because the temperature histories for 
the faster heating rate techniques do not have well defined dwell times, this was taken to be the time during which the specimen temperature was above $1275^{\circ} \mathrm{C}$ in all cases. Also included in Fig. 3 are results from Mazaheri et al. [18] using the same heating rate and same Tosoh powders (except for a binder addition) as the $\mathrm{CH}$ specimens used here. These agree well with our $\mathrm{CH}$ specimens.

The results in Fig. 3 show that the time required for full densification was reduced dramatically by rapid heating and that this occurred using heating methods which do not involve the application of electric fields to the specimen, as well as for flash sintering. The reduction in sintering time increased with heating rate. The time taken to reach a given density was reduced by about a factor of 20 compared with conventional heating for the FI specimens and the corresponding time reduction for SHS and FS specimens was between 2 and 3 orders of magnitude.

\section{Discussion}

The most important conclusions of this work are that (i) for a constant sintering temperature, very rapid heating leads to an enormous acceleration in the sintering rate of 3YSZ compared with specimens under conventional heating rates and the same dwell temperature, and (ii) this occurs with or without the presence of an electric field. That this was observed at constant maximum temperature is particularly significant since many $20^{\text {th }}$ century investigations of fast firing involved higher maximum temperatures than are used conventionally [12-14] making it difficult to separate the effect of heating rate from the effect of dwell temperature.

In view of the significance of these conclusions, it is important to rule out experimental artefacts. The clearest case is for the $\mathrm{Fl}$ specimens. These were sintered in the same furnace as the $\mathrm{CH}$ specimens, so all experimental factors were identical for these two sets of specimens except for the heating rates. The 
clear reduction of time required to reach a given density can therefore only be attributed to the faster heating.

This is apparently at odds with the conclusions of Chen and Mayo [15] who found no effect of heating rate on sintering of the same powders using similar heating methods to our Fl samples. However, the fastest heating rate used in [15] was $200^{\circ} \mathrm{C} / \mathrm{min}\left(3.3^{\circ} \mathrm{C} / \mathrm{s}\right)$, which is 15 times slower than the heating rate for the Fl specimens in this work. We conclude that very rapid heating rates are required to accelerate the sintering.

None of the unavoidable variations and uncertainties in the thermal conditions in the different heating methods works in favour of more rapid sintering in the SHS and FI specimens so these cannot be used to explain the accelerated sintering of the specimens heated rapidly without an electric field. The maximum temperatures for the SHS and FI specimens in Table 1 are, if anything, overestimates because the internal specimen temperature will have lagged behind that of the exterior thermocouple. In any case, even the nominal maximum temperatures for the SHS specimens ( 1301 and $1287^{\circ} \mathrm{C}$ ) were below those of the $\mathrm{FS}$ and $\mathrm{CH}$ specimens $\left(1347\right.$ and $1315^{\circ} \mathrm{C}$ respectively). The adiabatic temperature for the SHS reactants can be estimated using the method described in [19] as $1339{ }^{\circ} \mathrm{C}$. Even if the SHS specimens had reached this theoretical maximum temperature, the extra $24{ }^{\circ} \mathrm{C}$ compared with the $\mathrm{CH}$ specimens would have accelerated the sintering rate by only $73 \%$ based on an activation energy for conventional sintering of Tosoh $3 Y S Z$ of $485 \mathrm{~kJ} / \mathrm{mol}$ [18], whereas the experimental result was an acceleration of over 2 orders of magnitude.

The temperature gradients from the "outside-in" SHS heating may in some circumstances also inhibit sintering because of the possible formation of an external shell of densified ceramic during initial 
heating which could then slow the shrinkage of the interior [15]. In contrast, the "inside out" temperature gradients in the FS specimens may have the opposite effect, whereby the shrinkage from the rapid sintering of the hot interior would tend to aid the densification of the cooler exterior.

Finally, the $\mathrm{CH}$ specimens spent a long period heating to the final temperature, which would also have contributed to the sintering. It is concluded that experimental uncertainties cannot explain the accelerated sintering for the $\mathrm{FI}$ and SHS specimens; if anything the acceleration due to rapid heating is even greater than the raw results suggest.

The precise temperature during flash sintering is also uncertain. The method for temperature estimation assumes uniform temperature within the specimen whereas the steady state condition of finite element modelling of the full sintering process of these specimens (not shown here) suggests a temperature variation of about $\pm 50{ }^{\circ} \mathrm{C}$ about the mean in the section of the specimen analysed. The method also ignores extra heat generation due to contact resistance, and additional heat loss mechanisms - by conduction to the ends/wires, convection and by the electroluminescence which has been reported [20]. Modelling suggests that most of these effects are small but the contribution of electroluminescence is unknown. However, the method has been shown to give accurate estimates of the steady state mean temperature by comparison with independent measurements [20] which gives some confidence that the errors involved are relatively small.

The uncertainties in the FS specimen temperatures discussed and the difference between the maximum and steady state temperature (Table 1 ) are all $~ \pm 50{ }^{\circ} \mathrm{C}$. Assuming an activation energy for conventional sintering of $485 \mathrm{~kJ} / \mathrm{mol}$ [18] as above, this temperature range corresponds to a change in the sintering rate of the FS specimens by a factor of $\sim \pm 3$. This is very much less than the acceleration by more than 2 
orders of magnitude of sintering of the FS specimens compared with the $\mathrm{CH}$ specimens shown in Fig. 3, confirming that this is not simply an artefact of errors in temperature measurement for the FS specimens.

The fact that the SHS and FS specimens show comparable sintering behaviour with similar temperature profiles, regardless of the presence or absence of an electric field, implies that the rapid densification in flash sintering of 3YSZ is caused mainly by the indirect effect of the rapid heating resulting from the application of an electric field rather than any direct effect of the electricity on the net transport of matter. This is not to say that there is no effect of the electricity. 3YSZ is an ionic conductor and the currents used in the FS experiments here represent a considerable flux of oxygen ions. It would be surprising if there were absolutely no effect of this on sintering. There are also several convincing examples demonstrating the influence of electric fields on grain growth in YSZ [21,22]. The uncertainty in specimen temperatures also makes the comparison between the SHS and FS results imprecise. However, although a contribution from the direct effect of the electric field cannot be ruled out, it is clear by comparison with the SHS specimens in this work that the high heating rate in flash sintering is a major factor in the rapid sintering observed.

The reasons for the acceleration of sintering are under investigation and will not be discussed in detail here. However, the following general considerations are worthy of note:

1. The discussion of fast firing in the second half of the $20^{\text {th }}$ century identified the relative suppression of coarsening mechanisms such as grain growth [10] and neck growth by surface diffusion which compete with densification $[13,14,23]$, as possible reasons for the positive effect of rapid heating. As sintering 
rate is typically proportional to $1 / D^{4}$, where $D$ is grain size, small differences in relative coarsening rates could make a significant difference to sintering rates [23].

2. It has previously been suggested that local Joule heating at grain boundaries during flash sintering causes local heating, or even melting, and a consequent acceleration of sintering $[2,8]$. This idea has been criticised on the basis that thermal conduction rapidly damps out any local heating at grain boundaries [3]: the time $t$ taken for temperature to equilibrate over a distance $x$ is $\sim x^{2} / \alpha$ where $\alpha$ is the thermal diffusivity. With a grain size of $\sim 1 \mu \mathrm{m}$ and a thermal diffusivity for $3 Y S Z$ of $7 \times 10^{-7} \mathrm{~m}^{2} \mathrm{~s}^{-1}$ [17] the time for equilibration between the grain and the grain boundary is only $\sim 1 \mu \mathrm{s}$, whereas flash sintering takes place over several seconds. The very rapid sintering in the absence of an electric current reported here is also incompatible with melting of the $3 Y S Z$ : its melting point is about $2700{ }^{\circ} \mathrm{C}$ - well beyond any possible temperature reached in the FH and SHS experiments. However, it is noted that any surface impurities with low melting point but which would avoid melting during conventional heating rates by decomposing, dispersing into solid solution or reacting with the YSZ to form high melting point phases, may form a transient liquid phase during rapid heating, as melting is likely to be faster than either decomposition, dissolution or reaction.

3. It has recently been tentatively suggested that very rapidly formed grain boundaries may not have time to relax to their equilibrium structures during rapid heating [24]. Such non-equilibrium grain boundaries may have higher diffusion coefficients and may persist for some time because of the requirements for all the boundaries surrounding a grain to find their lowest energy misorientation, boundary plane and relative grain translation. Similar ideas could be expressed in terms of timedependent complexion transitions [25]. The similar shapes of the plots for the $\mathrm{FH}$ and $\mathrm{CH}$ specimens in 
Fig. 3 suggests that all stages of sintering are accelerated, consistent with these ideas, but further investigation of this possibility is needed.

The present results apply to 3YSZ but the extent to which the conclusions apply to other ceramics still needs to be established. Most reports in the literature concentrate on the conditions for the onset of the flash event and the electrical response but details of sintered densities are sparse. Investigations of flash sintering of $\mathrm{SiC}$, for example, show that it is difficult to attain full density by flash sintering in that ceramic $[26,27]$.

A better understanding of these effects will enable flash sintering and other novel methods for rapid heating to be harnessed more effectively for the development of new ceramics and improved methods of manufacture. Flash sintering appears to be a particularly promising method of realising the potential of fast firing because the resistive heating is applied throughout the ceramic, avoiding the problems of heat transfer, thermal shock and differential densification [15] encountered with external heating methods.

\section{Conclusions}

1. Rapid heating can accelerate the sintering of 3YSZ by over 2 orders of magnitude compared with conventional heating to the same temperature, with or without the involvement of electric fields or currents.

2. The results imply that the primary reason for rapid densification in flash sintering of 3YSZ is the rapid Joule heating involved rather than a direct effect of the electric field on mass transport or a higher maximum temperature. 


\section{Acknowledgements}

The authors are grateful to the National Natural Science Foundation of China for financial support under grants 51521001 and 51672197 and to Chongjun Xu for help in conducting the SHS experiments. The authors of [18] are thanked for making their original data on sintering of Tosoh 3YSZ powders available.

\section{References}

1. P.B. Vandiver, O. Soffer, B. Klima, J. Svoboda, J, The origins of ceramic technology at Dolni-Vestonice, Czechoslovakia, Science 246 (1989) 1002-1008.

2. M. Cologna, B. Rashkova, R. Raj, Flash sintering of nanograin zirconia in $<5 \mathrm{~s}$ at $850 \circ \mathrm{C}, \mathrm{J}$. Am. Ceram. Soc. 93 (2010) 3556-9.

3. R.I. Todd, E. Zapata-Solvas, R.S. Bonilla, T. Sneddon, P.R. Wilshaw, Electrical characteristics of flash sintering: thermal runaway of Joule heating. J. Eur. Ceram. Soc. 35 (2015) 1865-1877.

4. Y.Y. Zhang, J.I. Jung, J. Luo, Thermal runaway, flash sintering and asymmetrical microstructural development of $\mathrm{ZnO}$ and $\mathrm{ZnO}-\mathrm{Bi} 2 \mathrm{O} 3$ under direct currents, Acta Mater. 94 (2015) 87-100.

5. E. Bichaud, J.M. Chaix, C. Carry, M. Kleitz, M.C. Steil, Flash sintering incubation in $\mathrm{Al}_{2} \mathrm{O}_{3} / \mathrm{TZP}$ composites, J. Eur. Ceram. Soc. 35 (2015) 2587-2592.

6. J.G.P. da Silva, H.A. Al-Qureshi, F. Keil, R. Janssen, A dynamic bifurcation criterion for thermal runaway during the flash sintering of ceramics, J. Eur. Ceram. Soc. 36 (2016) 1261-1267.

7. M. Biesuz, V.M. Sglavo, Flash sintering of alumina: Effect of different operating conditions on densification, J. Eur. Ceram. Soc. 36 (2016) 2535-2542.

8. R. Chaim, Liquid Film Capillary Mechanism for Densification of Ceramic Powders during Flash Sintering, Materials 9 (2016) 280.

9. M. Cologna, J.S.C. Francis, R. Raj, Field assisted and flash sintering of alumina and its relationship to conductivity and MgO-doping, J. Eur. Ceram. Soc. 31 (2011) 2827-2837.

10. P. Vergnon, F. Juillet and S.J. Teichner, Influence de la vitesse de montée en temperature sur le frottage d'alumine pure en particules homodispersée, Rev. Hautes Tempér. et Réfract. 3 (1966) 409-419. 11. I. Wynn-Jones and L.J. Miles, Production of ?-Al2O3 Electrolyte, Proc. Br. Ceram. Soc. 19 (1971) 16178.

12. M.P. Harmer, E.W. Roberts and R.J. Brook, R. J., Rapid sintering of pure and doped ?-Al2O3, Trans.

Br. Ceram. SoC. 78 (1979) 22-5.

13. E.L. Kemer and D.L. Johnson, Microwave plasma sintering of alumina, Am. Ceram. Soc. Bull. 64 (1985) 1132-36.

14. M.P. Harmer and R.J. Brook, Fast Firing: microstructural benefits, J. Brit. Ceram. Soc. 80 (1981) 147-8. 15. D.J. Chen and M.J. Mayo, Rapid rate sintering of nanocrystalline $\mathrm{ZrO}_{2}-3$ mol\% $\mathrm{Y}_{2} \mathrm{O}_{3}$, J. Am. Ceram. Soc. 79 (1996) 906-12.

16. R. Raj, Joule heating during flash-sintering, J. Eur. Ceram. Soc. 32 (2012) 2293-2301.

17. Y. Motohashi, T. Shibata, S. Baba, M. Ishihara, T. Hoshiya, Thermal conductivity of superplastically deformed 3Y-TZP, Mater. Trans. 43 (2002) 2473-9. 
18. M. Mazaheri, A. Simchi, M. Dourandish, F. Golestani-Fard, Master sintering curves of a nanoscale 3YTZP powder compacts, Cer. Int. 35 (2009) 547-554.

19. J.B. Holt and Z.A. Munir, J. Mat. Sci. 21 (1986) 251-259

20. K. Terauds, J.M. Lebrun, H.H. Lee, T.Y. Jeon, S.H. Lee, J.H. Je and R. Raj, Electroluminescence and the measurement of temperature during Stage III of flash sintering experiments, J. Eur. Ceram. Soc. 35

(2015) 3195-3199.

21. D. Yang, R. Raj, and H. Conrad, 'Enhanced sintering rate of zirconia (3Y-TZP) through the effect of a weak dc electric field on grain growth,' J. Am. Ceram. Soc. 93 (2010) 2935-2937.

22. S. Ghosh, A.H. Chokshi, P. Lee and R. Raj, A huge effect of weak dc electrical fields on grain growth in zirconia, J. Am. Ceram. Soc. 92 (2009) 1856-1859.

23. D.L. Johnson, Ultra-rapid sintering of ceramics, in: D.P. Uskoković, H. Palmour III, R.M. Spriggs (Eds.), Science of Sintering, Plenum Press New York, 1989, pp. 497-506.

24. J.Y. Zhang, F.C. Meng, R.I. Todd and Z.Y. Fu, The nature of grain boundaries in alumina fabricated by fast sintering, Scripta Mater. 62 (2010) 658-661.

25. P.R. Cantwell, S. Ma, S.A. Bojarski, G.S. Rohrer, M.P. Harmer, Expanding time-temperaturetransformation (TTT) diagrams to interfaces: A new approach for grain boundary engineering, Acta Mater. 106 (2016) 78-86.

26. E. Zapata-Solvas, S. Bonilla, P.R. Wilshaw, R.I. Todd, Preliminary investigation of flash sintering of SiC, Journal of the European Ceramic Society 33 (2013) 2811-2816.

27. VM Candelario, R Moreno, RI Todd, AL Ortiz, Liquid-phase assisted flash sintering of SiC from powder mixtures prepared by aqueous colloidal processing. J Eur Ceram Soc 37 (2017) 485-498 